\title{
Extinguishment of a Laminar Jet Diffusion Flame Using a Soap Bubble Filled with Nitrogen Gas
}

\author{
HIROYUKI TORIKAI, TAKUMI MURASHITA, AKIHIKO ITO, and TAKUMI METOKI \\ Graduate School of Science and Technology \\ Hirosaki University \\ Bunkyo-cho 3, Hirosaki, Aomori, Japan
}

\begin{abstract}
Inert gases, such as nitrogen, argon and carbon dioxide, are able to extinguish a fire more cleanly than water and dry chemical extinguishing agents. However, to extinguish the fire completely, a large amount of inert gas is needed to be released at the vicinity of the fire or into a confined space containing the fire. If a capsule is filled with an extinguishing inert gas, and ruptures due to contact with the flame zone, the high concentration extinguishing gas can be directly supplied to the fire. By using this capsule, it may be possible to increase the effectiveness and decrease the amount of the extinguishing inert gas needed in firefighting. In the present study, in order to clarify the fundamental characteristics of flame extinguishment by an inert gas capsule, extinguishment experiments of a methane-air laminar jet diffusion flame by a soap bubble capsule filled with nitrogen gas have been performed. Visualization of flow released from the bursting bubble has also been carried out by using laser tomography and schlieren techniques. Results show that, when the soap bubble bursts, two different kinds of nitrogen gas flow are formed. The first flow is generated by the pressure difference between the inside and outside of the soap bubble. The second flow is generated by the soap liquid film dynamics. Combined, these two flows of nitrogen gas extinguish the laminar jet flame. The first flow extinguishes the flame base locally, and the second flow leads to blow out of the whole flame.
\end{abstract}

KEYWORDS: extinguishment, jet flames, inert gas, soap bubble.

\section{NOMENCLATURE LISTING}

$h \quad$ position from burner rim ( $\mathrm{mm})$

$P \quad$ flame blowout probability (-)

$V \quad$ volume of nitrogen gas $\left(\mathrm{cm}^{3}\right)$

\author{
subscripts \\ $t \quad$ top of flame \\ $b \quad$ base of flame \\ ex extinguishment limit
}

\section{INTRODUCTION}

Water is widely used as a firefighting agent because of its fire suppression performance [1]. The thermal characteristics, such as heat capacity and the latent heat of vaporization, are suitable for removing heat from the combustion region. Moreover, the vapor produced from the phase change of liquid water contributes to flame extinguishment by reducing the oxygen concentration of the surroundings atmosphere, however, water damage to construction and electrical equipment, etc. occurs. Dry chemical powder is also used for firefighting and is effective in suppressing fire by interfering with the chemical chain reaction at the flame, however, extensive clean up of the area is required.

Inert gases (carbon dioxide, nitrogen or argon) can extinguish fire through oxygen reduction at the flame [2]. Inert gases are environmental friendly and do not cause the secondary damage that water and dry chemical powder do. Thus, inert extinguishing gases are able to extinguish a fire more cleanly than water and dry chemical powder. However, the extinguishing gas easily diffuses into and mixes with the surrounding air and its concentration rapidly decreases as it travels from the application location to the flame zone. Furthermore, inert gases do not have significant ability to extract heat from flame zone and fuel surface. Consequently, in order to reduce the oxygen concentration below the limiting value [3] and to extinguish the fire completely, a large amount of inert gas needs to be released at the vicinity of flame or into a confined space containing the fire. Particularly, in its use for confined space, complete evacuation of personnel is needed before the inert extinguishing gas is discharged. If the capsule, whose film inhibits inter-diffusion between the inner gas and the surrounding air, is filled with inert gas and the film ruptures due to contact with the flame, a high concentration inert gas can be easily transported through the 
atmosphere and directly supplied to the flame. Thus, by using this capsule, it may be possible to increase the effectiveness and decrease the amount of inert gas needed in firefighting.

In this study, in order to clarify the fundamental characteristics of flame extinguishment by an inert gas capsule, extinguishment experiments of a laminar jet diffusion flame by a soap bubble filled with nitrogen gas have been performed. A soap bubble can be used as a low-solubility gas capsule because the soap liquid film suppresses mixing between the filling gas and the surrounding air, and when a soap bubble contacts with the high temperature region of the flame, the liquid film ruptures instantaneously due to reduction of surface tension force. Moreover, the surface tension force causes a pressure difference between the inside and outside of the soap bubble. This pressure difference induces flow of the filling gas from the soap bubble towards the flame when the soap bubble bursts. In addition, it is very easy to form a soap bubble and to reproduce the rupture process of the soap liquid film. Thus, the soap bubble is suitable for investigation of the flame extinguishing method by using it as a capsule. In this study, visualization of flow released from the bursting bubble has also been carried out by using laser tomography and schlieren techniques.

\section{EXPERIMENTAL APPARATUS AND METHOD}

\section{Laminar Jet Diffusion Flame and Soap Bubble}

Figure 1 shows drawing of the experimental apparatus. A laminar methane-air jet diffusion flame was formed with a SUS 304 stainless tube burner. The inner and outer diameter of the tube was $2.5 \mathrm{~mm}$ and $3 \mathrm{~mm}$, respectively. The volumetric flow rate was measured with a capillary flow meter. The crosssectional mean flow velocity was calculated from dividing the volumetric flow rate by the cross-sectional area of the stainless tube. The ratio of the length to the diameter of the tube burner was 130 . Therefore, the length of the burner tube was long enough to form fully developed Hagen-Poiseuille flow at the burner exit. Figure 2 shows measured data of distance from the top and base position of the flame to the burner rim on the centerline of the methane jet. The horizontal axis is the cross-sectional mean flow velocity. As the flow velocity increases, the flame height which is the difference between the top and the bottom position of the flame increases linearly. For a laminar jet diffusion flame, there is linear dependency between flame height and flow velocity [4]. Therefore, in the experimental velocity range, the flame was formed as a laminar flame and also the flame base was attached to the burner rim. In addition, the Reynolds number of methane flow in the burner tube was calculated by using the cross-sectional mean flow velocity, methane dynamic viscosity at standard conditions, and the tube diameter. The value of maximum Reynolds number in our experiments was approximately 900 and lower than that of a critical Reynolds number in tube flow. Therefore, the flow in the tube burner was also laminar.

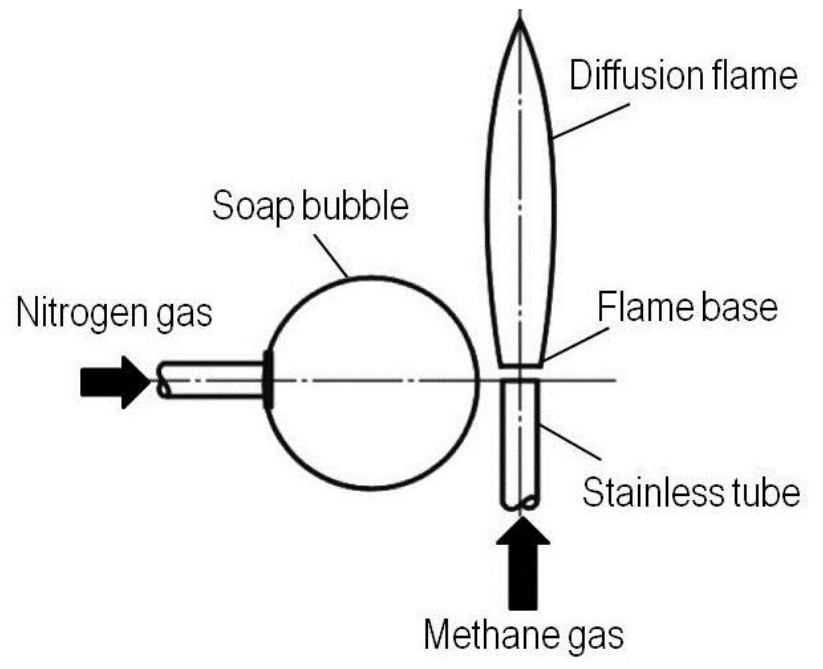

Fig. 1. Schematic of experimental set-up. 


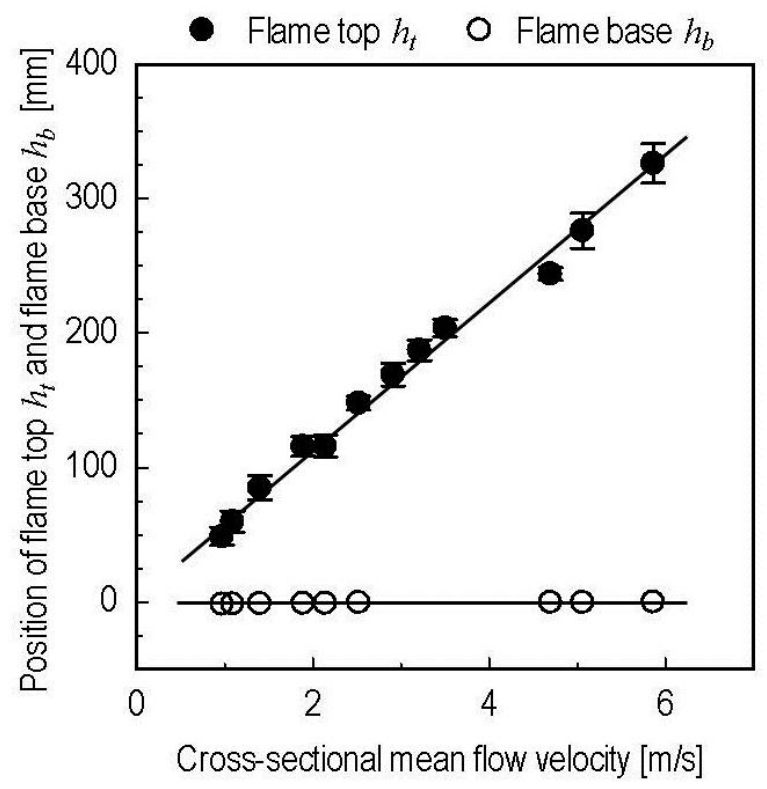

Fig. 2. Location of the flame top and flame base of methane-air jet diffusion flame.

The soap bubble was inflated with nitrogen gas and formed at the end of the metal tube as shown in Fig. 1 . A common soap liquid leak detector (Swagelok, Snoop) was used as soap solution. The filled gas volume in a soap bubble was determined from multiplying the constant flow rate of nitrogen gas by the elapsed time from application of soap solution to the mouth of the nitrogen gas issuing tube. The volumetric flow rate of nitrogen gas was measured with a capillary flow meter. The pressure difference between the inside and outside of a soap bubble was measured with an inclined liquid column manometer (KIMO, HP5). Figure 3 shows the relationship between pressure difference and the radius of a soap bubble. The value of the pressure difference decreases monotonically as the radius of the soap bubble increases, and is very small compared with the value of atmospheric pressure. Hence, if the liquid film of a soap bubble ruptures, the filling gas flow is driven by the pressure difference. In addition, surface tension was calculated according to the equation derived from Young-Laplace equation [5]. The value of the surface tension was $22.5 \mathrm{mN} / \mathrm{m}$ approximately. Using an electronic weight scale (A\&G, GF-6100) with $0.01 \mathrm{~g}$ resolution, the total mass of twenty soap bubbles was measured and the mass of one soap bubble was calculated by dividing the total mass by the number of soap bubbles. In the measurements, all soap bubbles were put into a closed plastic container to prevent water evaporation. Figure 4 shows the relationship between the mass of the liquid soap film and the soap bubble size. The plotted data were averaged from three different measurements. The mass of the soap liquid film increased with increase in its bubble size. However, it was found that the mass variation of the soap bubble in our experimental conditions was limited within the range from several to tens of milligrams.

The extinguishment experiments by the inert-gas soap bubble capsule were performed in the following way. First, the stable jet diffusion flame and inert-gas soap bubble were formed at a certain fuel velocity and nitrogen gas volume, respectively. Second, the capsule was transferred laterally to the flame base of the diffusion flame, and was burst by being contacted with the thermal boundary of the flame base region. Then, we checked whether the flame was extinguished or not visually. When the whole flame was blown off, we recorded it as successful extinguishment by the inert-gas soap bubble capsule. The probability of extinguishment, $P$, was computed as the ratio of the number of successful extinguishments to the number of total experiments of 30 . The centerline of the nitrogen issuing tube was always adjusted to the height of the burner rim as shown in Fig. 1. The experiment time between the ignition and the contact of the inert-gas soap bubble capsule with the flame was always less than thirty seconds. Therefore, during the extinguishment experiment, the burner tube was kept at low temperature and its temperature did not affect the stability of the flame. In addition, a soap bubble capsule filled with air did not extinguish the flame. Thus, it was impossible to extinguish the flame by using only a soap bubble and the oxygen dilution effect of the inert gas was critical. 


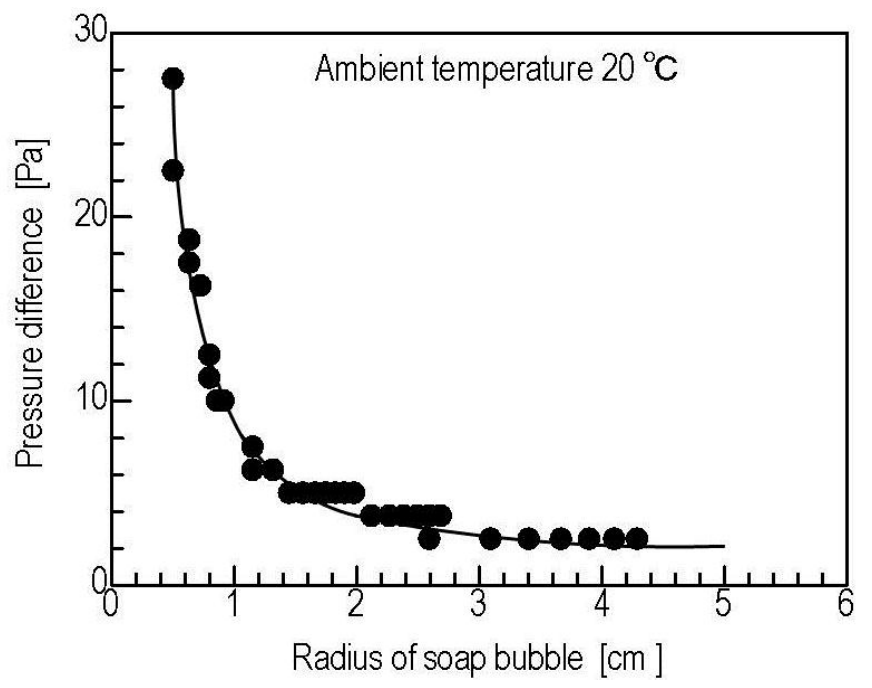

Fig. 3. Pressure difference between the inside and outside of soap bubble.

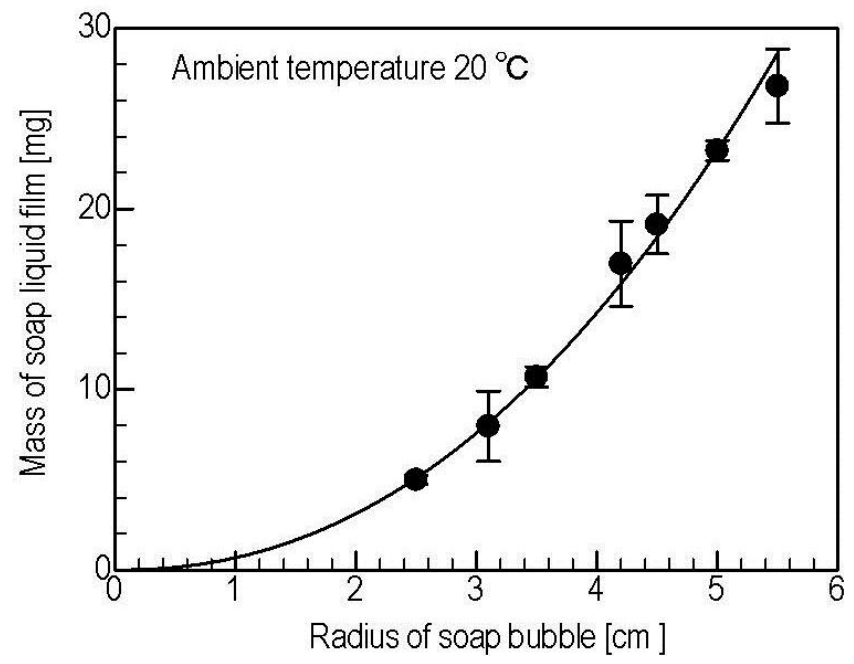

Fig. 4. Relationship between the mass of the soap liquid film and the soap bubble size.

\section{Visualization Method}

The behavior of gas flow released from bursting bubble was observed by using laser tomography technique. By using a laser light sheet, this method visualizes the cross section of the flow seeded with light scattering particles. Figure 5 shows visualization method of laser tomography. Nd:YAG/YVO $\mathrm{Y}_{4}$ laser (Katokoken co. Ltd., PIV laser G50) was used as light source with power of $50 \mathrm{~mW}$ and wavelength of $532 \mathrm{~nm}$. The laser sheet thickness was approximately $1 \mathrm{~mm}$. Silicon oil was atomized by a glass nebulizer, and its droplets were seeded to the nitrogen gas flow. The silicon oil droplet had the nominal diameter of $0.002 \mathrm{~mm}$ and the boiling point of $300^{\circ} \mathrm{C}$ [6]. The tomography images were recorded by high-speed camera (CASIO, EX-F1) at the exposure time of $1 / 320 \mathrm{~s}$ and frame rate of $300 \mathrm{fps}$. In the vitalization experiment, the soap liquid film was ruptured at the side of the soap bubble by using metal wire as shown in Fig. 5.

Figure 6 shows the optical arrangement of schlieren method. By using schlieren method, variation of concentration and temperature in the flow field was visualized. Concave mirrors with focal length of $200 \mathrm{~cm}$ and diameter of $20 \mathrm{~cm}$ were used. Halogen lamp (300 W) was used as light source. The schlieren images were recorded with the same high-speed camera as used in the laser tomography. Figure 7 shows the visualized images of the jet diffusion flame and the soap bubble filled with nitrogen gas. The flame 
height was $200 \mathrm{~mm}$ and the nitrogen gas volume is $28 \mathrm{~cm}^{3}$ (soap bubble radius $19 \mathrm{~mm}$ ). The cross-sectional mean methane flow velocity was $3.5 \mathrm{~m} / \mathrm{s}$. Figures $7 \mathrm{a}$ and $\mathrm{b}$ show direct and schlieren images, respectively. In Fig. 7b, thermal boundary of the flame zone in the jet diffusion flame is observed clearly.

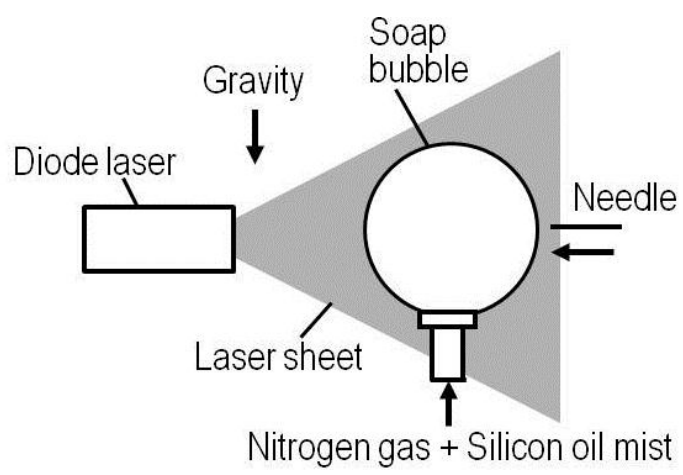

Fig. 5. Laser tomography method.

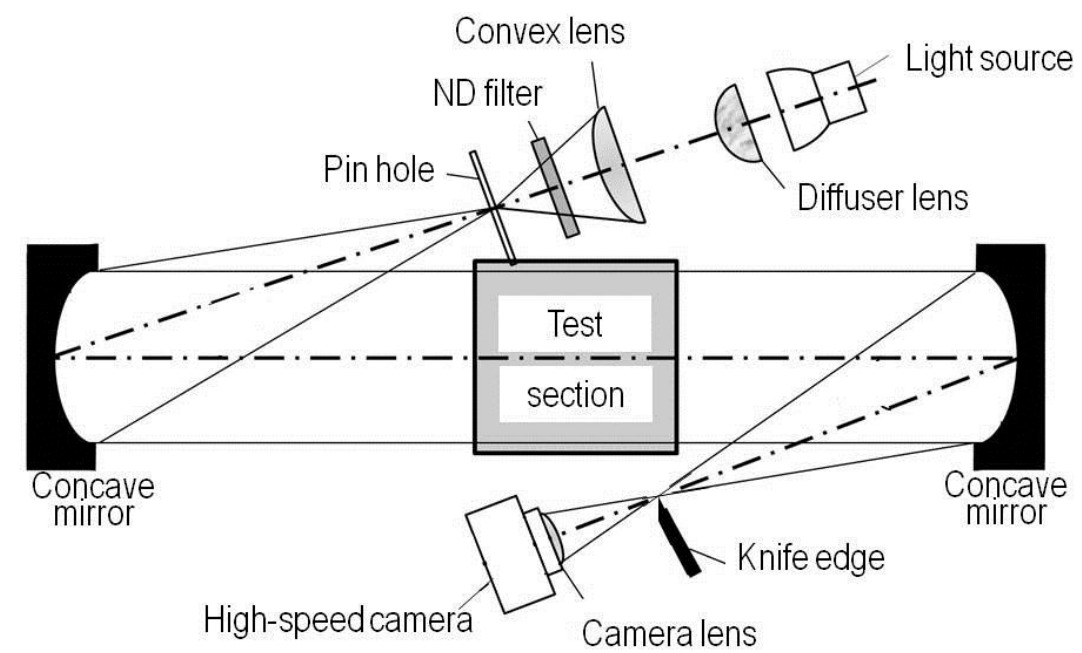

Fig. 6. Optics arrangement of schlieren visualization method.

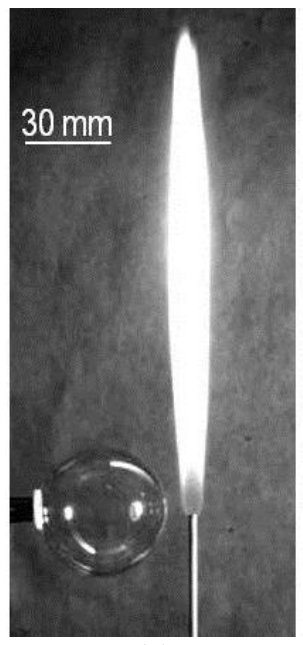

(a)

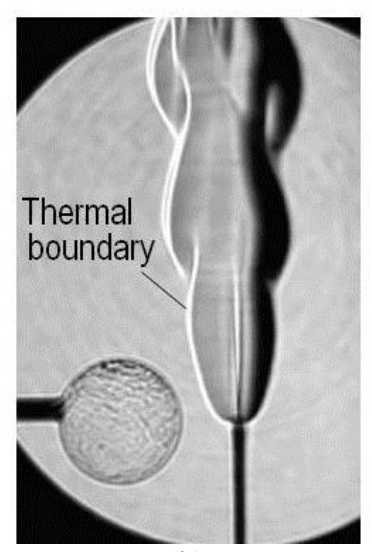

(b)

Fig. 7. Image of jet flame and soap bubble filled with nitrogen gas: (a) direct image; (b) schlieren image. 


\section{RESULTS AND DISCUSSION}

\section{Bursting of Soap Bubble}

Figure 8 shows a series of sequential direct images of the inert-gas soap bubble capsule bursting. The metal halide lamp (Photron, HVC-UL) at the power of $250 \mathrm{~W}$ was used. These direct images were recorded with high speed camera at frame rate of $1200 \mathrm{fps}$ and exposure time of 1/1250 s. The filled nitrogen gas volume into the soap bubble was $300 \mathrm{~cm}^{3}$ (soap bubble radius $41.5 \mathrm{~mm}$ ). The wire for rupture of soap film was moved from the right side of the image.

After the soap liquid film starts to rupture at $0 \mathrm{~ms}$, the edge of the soap liquid film is driven by surface tension force and progresses rapidly from the right side to the left side of the images in Fig. 8. The liquid film is atomized into the droplets at the edge of the soap liquid film, which are shown as white particles in each image. At between $19.2 \mathrm{~ms}$ to $22.5 \mathrm{~ms}$, the soap liquid film shrinks into the small area and the soap liquid droplets splashes in all directions. It is found that in the image at $25.8 \mathrm{~ms}$, the small amount of the splashed soap liquid flies to the right and upper oblique direction in the image. The drainage of liquid film due to gravity leads to reduce the film thickness of the upper area of the soap bubble, and the moving velocity of the liquid film edge depends on the inverse of film thickness [7,8]. As a result, it is seen that the upper edge of the soap liquid film moves faster than the lower edge of that at between $9.2 \mathrm{~ms}$ to $15.8 \mathrm{~ms}$, and the splashing area of the liquid film is located below the center of the soap bubble. The similar bursting process of soap liquid film is observed for other soap bubble radiuses.

\section{Nitrogen Gas Motion of Bursting Soap Bubble}

Figure 9 shows a series of sequential laser tomographic images of the inert-gas soap bubble capsule bursting process. The laser tomographic image indicates the nitrogen gas. The nitrogen gas volume in the soap bubble was $300 \mathrm{~cm}^{3}$ (soap bubble radius $41.5 \mathrm{~mm}$ ). The soap film rupture was initiated from the right side of the image.
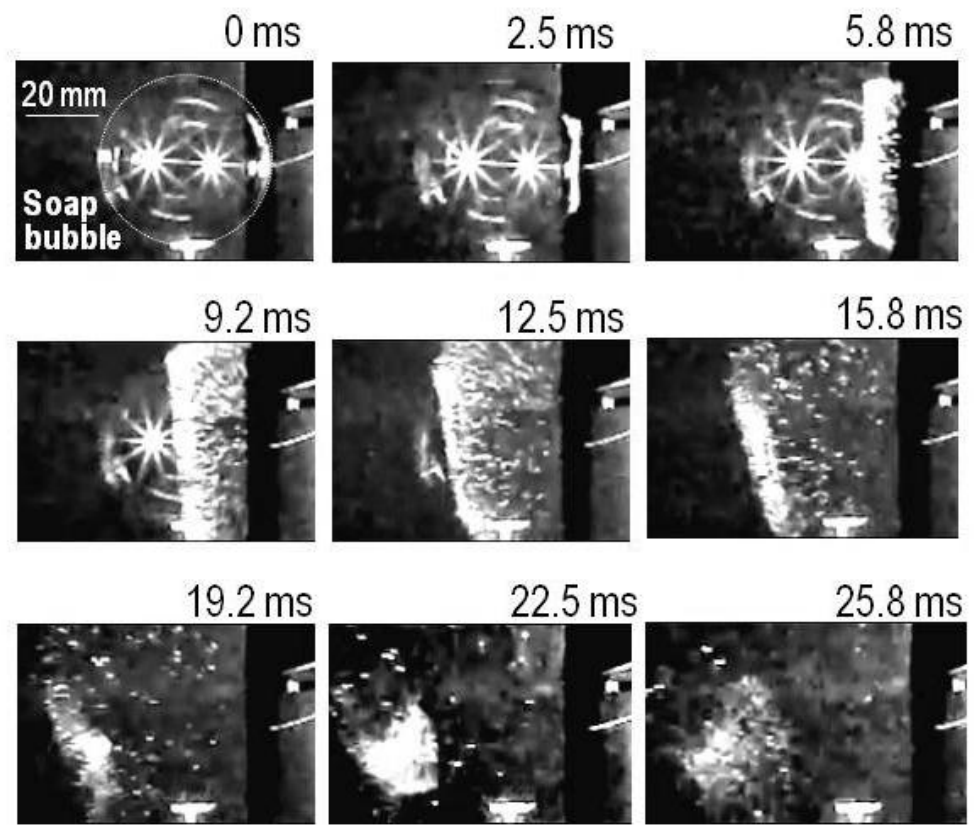

Fig. 8. Series of sequential direct images of bursting process of a soap bubble. 


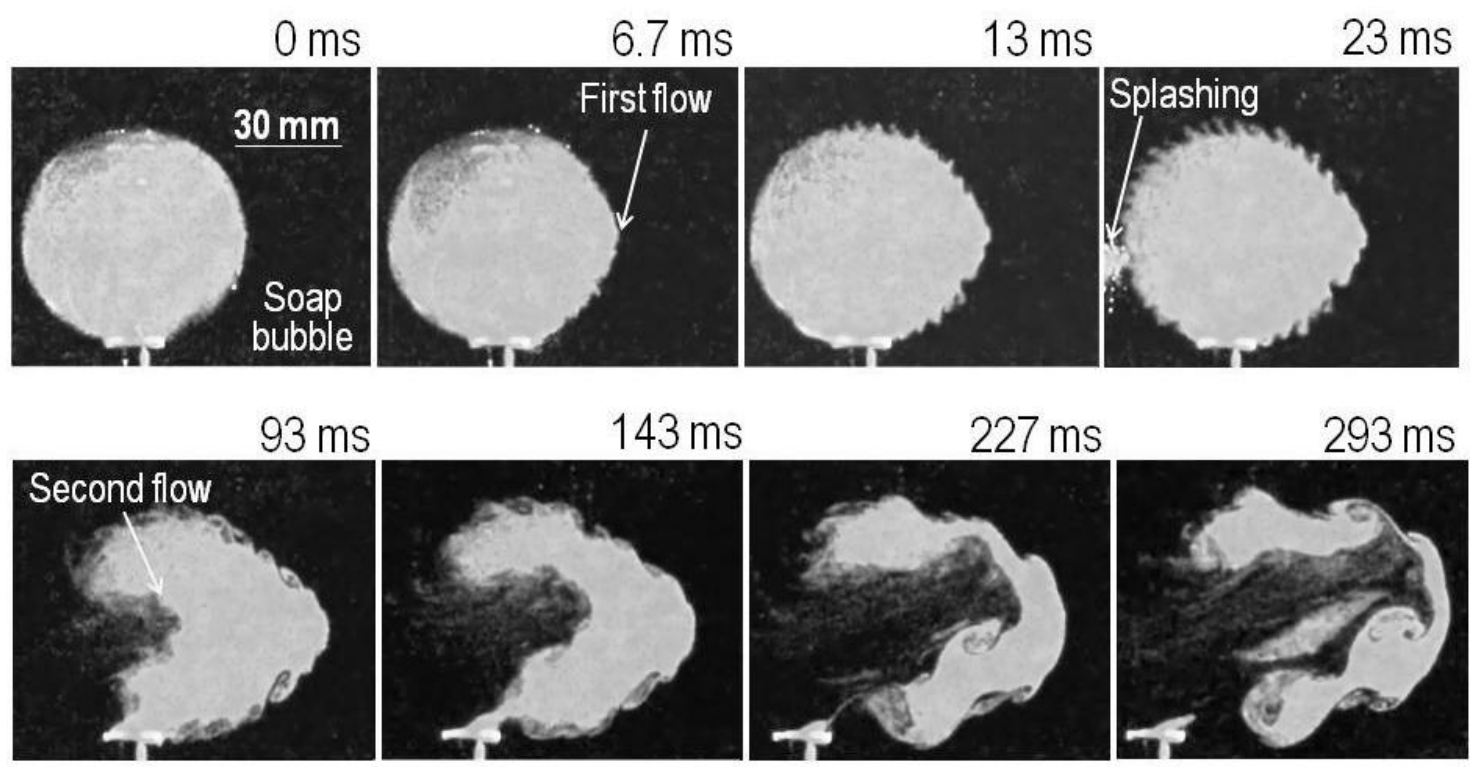

Fig. 9. Series of sequential laser tomographic images of the bursting soap bubble.

First, at between $6.7 \mathrm{~ms}$ and $23 \mathrm{~ms}$, it is seen that the nitrogen gas starts to flow from the rupture point to the right direction of the image. On the other hand, the edge of the soap liquid film moves to the left direction in the image and splashes at $23 \mathrm{~ms}$ as well as the image at $22.5 \mathrm{~ms}$ in Fig. 8. Moreover, after the soap liquid edge passes, it is observed that the Kelvin-Helmholtz instability occurs at the boundary between the nitrogen gas and the surrounding air. After the liquid soap film concentrates to the small area as shown in the image at $23 \mathrm{~ms}$, and splashes, it is found that at between $93 \mathrm{~ms}$ to $293 \mathrm{~ms}$, the nitrogen gas flow (or the air vortex ring) is generated at the splashing region of the soap liquid film, and progresses to the right and upper oblique direction in the image. This nitrogen gas flow is considered to be driven by the splashing soap liquid. Thus, when a soap bubble bursts, two different kinds of nitrogen gas flow are produced. The first flow is driven by the pressure difference between the inside and the outside of the soap bubble. The second flow is driven by the surface-tension-induced motion of the ruptured soap liquid film. The latter flow pushes the nitrogen gas forward to its travel direction. These flow characteristics were observed in other experimental condition.

\section{Flame Extinguishment by Using Soap Bubble Filled with Nitrogen Gas}

Figure 10 shows schlieren images of the successful blowout process of the laminar jet diffusion flame by the inert-gas soap bubble capsule. The flame height was $300 \mathrm{~mm}$ and the nitrogen gas volume is $300 \mathrm{~cm}^{3}$ (soap bubble radius $41.5 \mathrm{~mm}$ ). The mean methane flow rate was $5.6 \mathrm{~m} / \mathrm{s}$. At $0 \mathrm{~ms}$ in Fig. 10, the liquid film of the soap bubble contacts with the thermal boundary of the flame base. Then, the soap liquid film ruptures, and the edge of the liquid film progresses to the opposite side of the flame. At $17 \mathrm{~ms}$, the first nitrogen gas flow driven by the pressure difference between the inside and the outside of the soap bubble reaches the reaction zone of the flame base. As a result, at $50 \mathrm{~ms}$, the local extinction at the flame base region occurs due to reduction of oxygen concentration in the flame reaction zone, and the extinction area increases at $77 \mathrm{~ms}$. Then, the rest of the jet flame lifts off toward the downstream at $150 \mathrm{~ms}$. Finally, the whole flame is blown out at $360 \mathrm{~ms}$. Although it is difficult to see from Fig. 10 the motion of the second nitrogen gas flow driven by liquid film dynamics, the second nitrogen gas flow is generated and progresses from the left side to the right side of the images at between $150 \mathrm{~ms}$ to $203 \mathrm{~ms}$. In order to clarify the relation between the flame base behavior and the second nitrogen gas flow, the flame base location was defined as the lowest position of the thermal boundary on the center axis of the methane jet in the schlieren image, and was measured from the images of Fig. 10. 

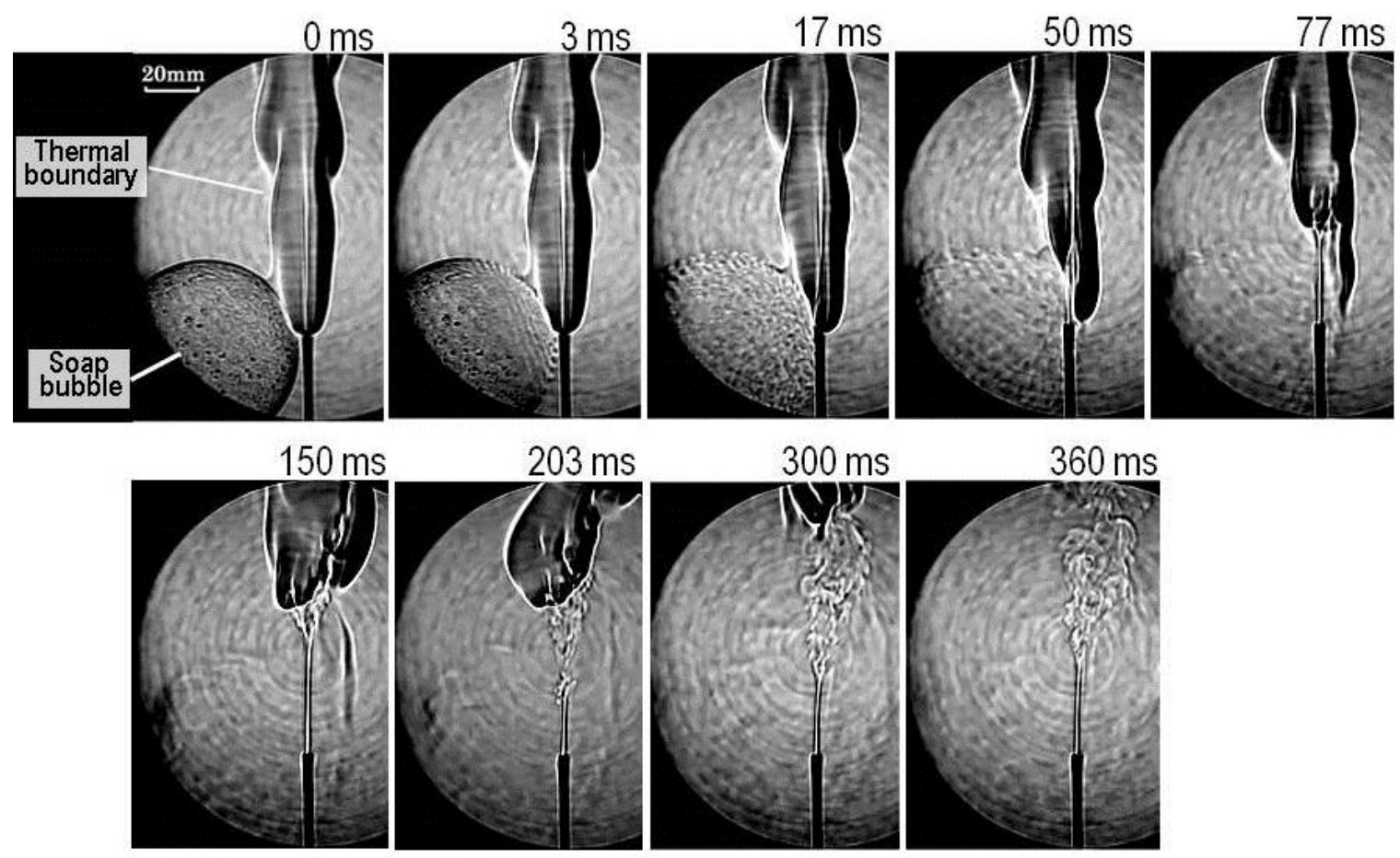

Fig. 10. Series of the sequential schlieren images of flame extinguishment by inert gas soap bubble.

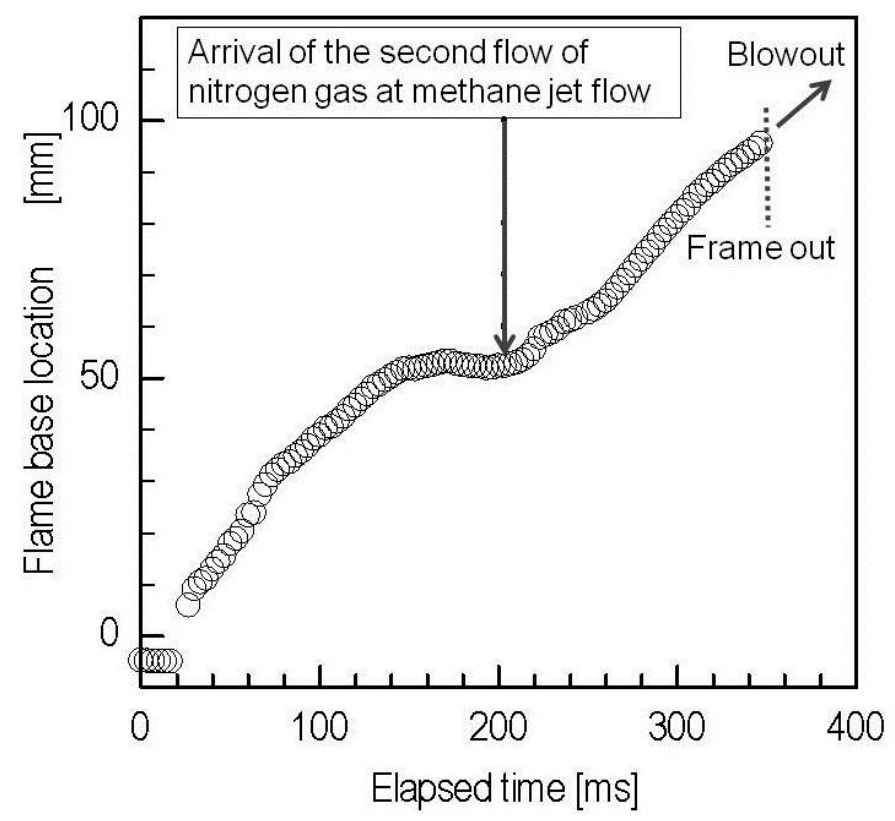

Fig. 11. Relationship between the flame base motion and the nitrogen gas flow driven by soap liquid film dynamics.

Figure 11 shows the results. The vertical axis indicates distance from flame base to the burner rim, and the upward direction is positive. From Fig. 11, it is seen that after the flame lifts off from the burner rim, the flame base location increases with time. However, the flame base motion is decelerated at $150 \mathrm{~ms}$ and stops at the height of $5 \mathrm{~cm}$ from the burner rim. This behavior indicates that the flame base is re-stabilized downstream because partially premixing between methane and oxygen in air occurs upstream of the lifted flame base and the flame base acquires the ability to propagate to upstream as a partially premixed flame. 
However, the second nitrogen gas flow driven by the soap liquid film motion arrives at the methane jet as shown in Fig. 11. Then the nitrogen gas is supplied again to the lifted flame base, and the flame base retreats downstream. Finally, the whole flame is blown out.

Figure 12 shows sequential schlieren images of the failed blowout process. The flame height was $300 \mathrm{~mm}$ and the nitrogen gas volume is $5 \mathrm{~cm}^{3}$ (soap bubble radius $11 \mathrm{~mm}$ ). The mean methane flow rate was $5.6 \mathrm{~m} / \mathrm{s}$. When the film of the inert-gas soap bubble capsule contacts with the thermal boundary of the jet flame, the soap bubble starts to burst. Then, the first nitrogen gas flow driven by the pressure difference between the inside and the outside of the soap bubble is supplied to the flame and extinguishes the flame base region locally due to reduction of oxygen concentration at $3 \mathrm{~ms}$ in Fig. 12. However, the lifted flame is stabilized downstream at $87 \mathrm{~ms}$. Although the second nitrogen gas flow driven by the soap liquid film motion reaches the methane jet, the burning velocity of the lifted flame base which is partially premixed flame, becomes larger than the velocity of the incoming flow to the flame base at $203 \mathrm{~ms}$. Finally, the stable jet diffusion flame is stabilized on the tube burner. Thus, for unsuccessful extinguishment cases, the nitrogen gas volume is too small to extinguish the whole flame.

\section{Probability of Extinguishment by Using Inert Gas Soap Bubble}

Figure 13 shows a typical profile of probability of extinguishment, $P$, as a function of nitrogen gas volume. The flame height was $15 \mathrm{~cm}$ and the cross-sectional mean methane flow velocity was $2.6 \mathrm{~m} / \mathrm{s}$. From Fig. 13 ,

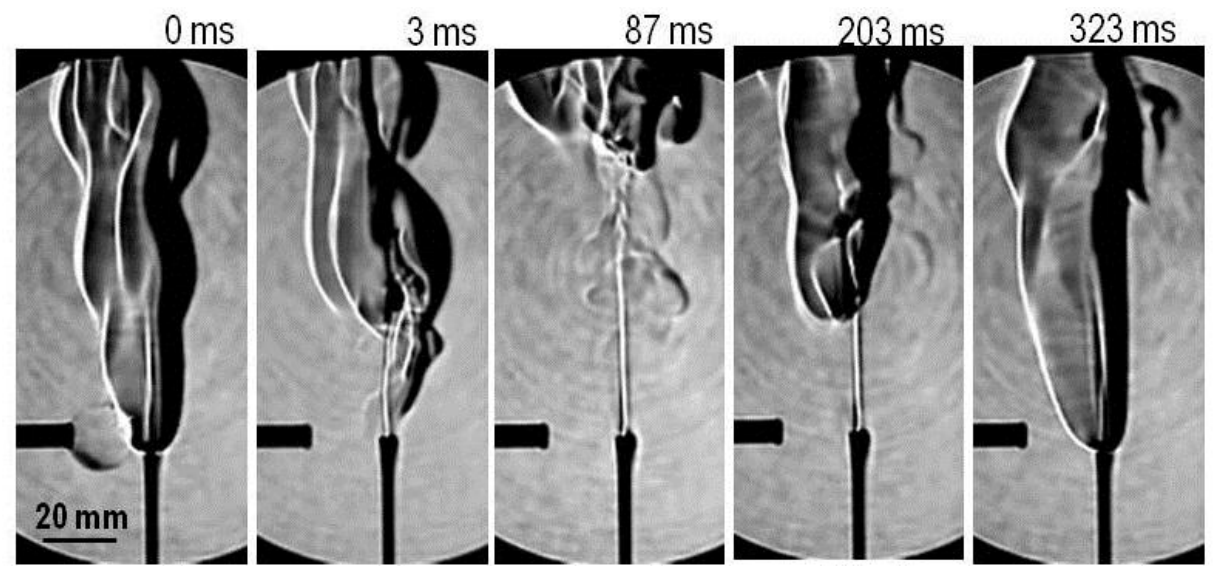

Fig. 12. Series of the sequential schlieren images of failed flame extinguishment.

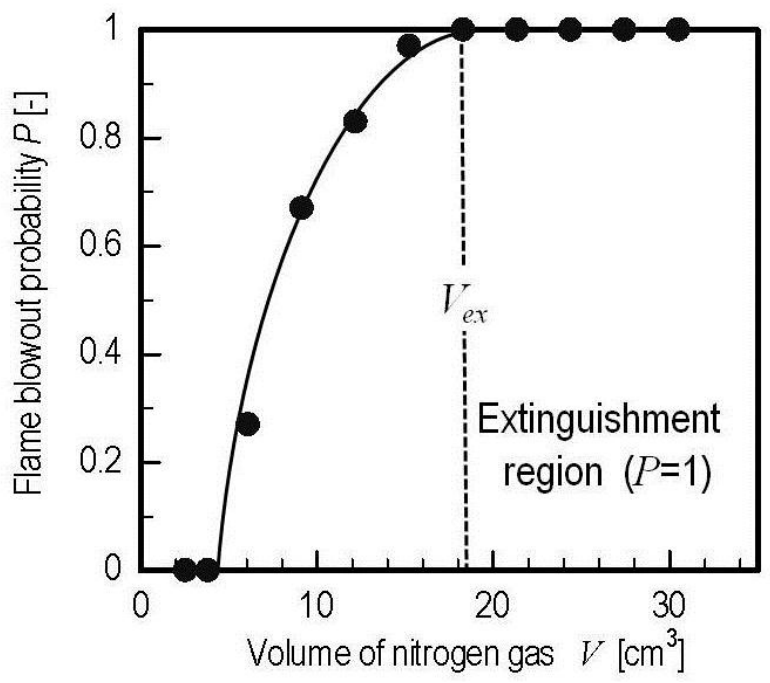

Fig. 13. Flame blowout probability as a function of nitrogen gas volume. 


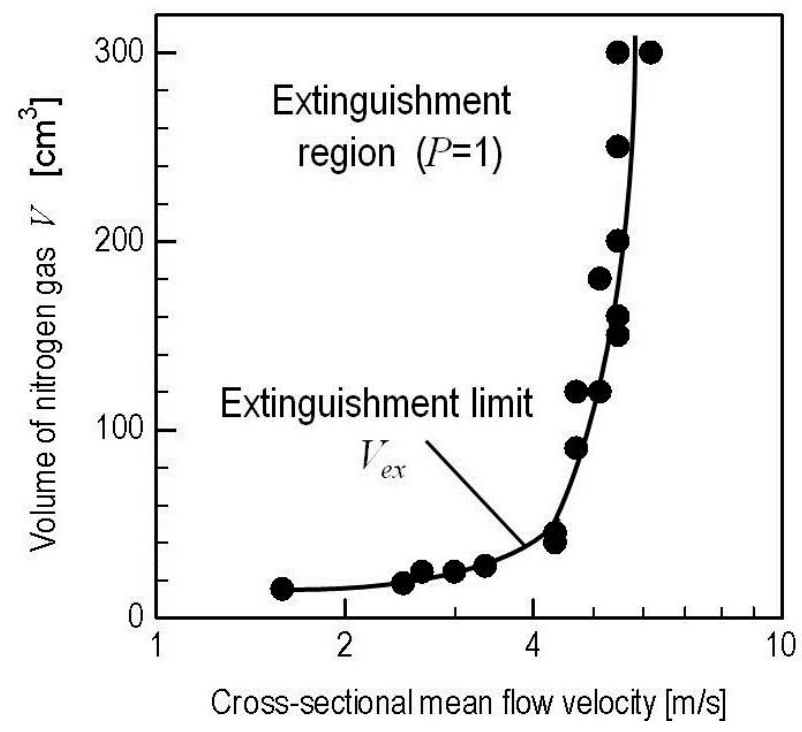

Fig. 14. Profile of extinguishment limit.

it is seen that as the nitrogen gas volume increases, flame blowout probability increases monotonically, and the extinguishment region in which $P$ always shows unity, appears. Moreover, the limitation values in the extinguishment region can be defined as the extinguishment limit, $V_{e x}$, which is the lower boundary of the extinguishment region. From the limit value, we can evaluate the extinguishing ability.

\section{Extinguishment Limit}

Figure 14 shows the profiles of the extinguishment limit of nitrogen gas volume. The vertical axis is nitrogen gas volume. The horizontal axis is the cross-sectional mean methane flow velocity, that is, the flame height. From Fig. 14, it is seen that when the methane flow velocity is less than $4-5 \mathrm{~m} / \mathrm{s}$ (flame height $280 \mathrm{~mm}$ ), the value of the extinguishment limit increases gradually with an increase in the fuel velocity. On the other hand, when the methane flow velocity is larger than 4-5 m/s, the value of extinguishment limit increases steeply as the mean fuel flow velocity increases. This tendency indicates that when the fuel flow velocity is relatively large, there is a critical value of the fuel flow velocity (or flame height), over which the jet diffusion flame can not be blown out by using the soap bubble filled with inert gas. Conversely, from the results in Fig. 14, it is considered that there is an upper limit to the transported gas volume of nitrogen to the flame region by the two flows generated from soap bubble bursting. As a result, it is found that when the mean fuel velocity is greater than about $6 \mathrm{~m} / \mathrm{s}$, the extinguishment region disappears regardless of the nitrogen gas volume filling in the soap bubble

\section{CONCLUDING REMARKS}

If a soap bubble capsule is filled with an extinguishing inert gas, and ruptures due to contact with the flame zone, high concentration extinguishing gas can be directly supplied to the flame. By using the capsule, it may be possible to increase the effectiveness and decrease the amount of the inert extinguishing gas needed in firefighting. A soap bubble can be used as a capsule of low solubility gases because the soap liquid film suppresses mixing between the filling gas in the soap bubble and the surrounding air. When a soap bubble contacts with the thermal boundary of a flame zone, the soap liquid film ruptures instantaneously due to reduction of surface tension. When a capsule is filled with an extinguishing inert gas and ruptures due to contact with the flame zone, high concentration extinguishing gas can be directly supplied to the flame.

In the present experimental study, in order to clarify the fundamental characteristics of flame extinguishment by the inert gas capsule, extinguishment experiments of a methane-air laminar jet diffusion flame by a soap bubble filled with nitrogen gas have been performed. Visualization of the flow from the bursting bubble has been carried out by using laser tomography and schlieren techniques.

From the experimental results, it is found that when the inert-gas soap bubble capsule bursts, two different kinds of the filling gas flow are formed. The first flow is generated by the pressure difference between the inside and outside of the soap bubble. The second flow is generated by the soap liquid film motion. It is 
seen that these two flows of nitrogen gas affect and extinguish the methane-air laminar jet diffusion flame. The first flow extinguishes locally the flame base region of the jet diffusion flame due to reduction of oxygen concentration in the reaction zone in the flame, and then, the lifted flame is formed and restabilized downstream. The second flow reaches the non-reacting methane jet and supplies nitrogen gas to the flame base of the lifted flame. Finally, the whole flame blowout occurs. However, it seems to be that there is an upper limit to the transported gas volume to the flame by these flows released from the inert-gas soap bubble capsule. Therefore, in our blowout experiments, when the mean fuel velocity is larger than 4$5 \mathrm{~m} / \mathrm{s}$, the extinguishment region in which the jet diffusion flame are always blown out by the inert gas soap bubble disappears regardless of the nitrogen gas volume filling in the soap bubble.

\section{REFERENCES}

[1] Grant, G., Brenton, J., and Drysdale, D., (2000) Fire Suppression by Water Sprays, Progress in Energy and Combustion Science 26(2): 79-130, http://dx.doi.org/10.1016/S0360-1285(99)00012$\underline{X}$

[2] Jarosinski, J., A., (1980) Survey of Recent Studies on Flame Extinction, Progress in Energy and Combustion Science 12(2): 81-116, http://dx.doi.org/10.1016/0360-1285(86)90014-6

[3] Ishizuka, S., and Tsuji, H., "An Experimental Study of Effect of Inert Gases on Extinction of Laminar Diffusion Flames," Symposium (International) on Combustion, 1981, 18: 695-703. http://dx.doi.org/10.1016/S0082-0784(81)80074-4

[4] Kuo, K. K., Principles of Combustion, John Wiley and Sons, 1986, pp.347-370.

[5] Weaire, D. and Hutzler, S., The Physics of Foams, Oxford University Press, 1999, p.21.

[6] Kitajima, A., Ueda, T., Matsuo, A., and Mizomoto, M., (1996) Experimental Investigation of the Flame Structure and Extinction of Turbulent Counterflow Non-Premixed Flames, Symposium (International) on Combustion 26(1): 137-143. http://dx.doi.org/10.1016/S0082-0784(96)80210$\underline{4}$

[7] Muller, F., Kornek, U., and Stannarius, R., (2007) Experimental Study of the Bursting of Inviscid Bubbles, Physical Review E 75(6), http://dx.doi.org/10.1103/PhysRevE.75.065302.

[8] Evers, L. J., Shulepov, Y., and Frens, G., (1997) Bursting Dynamics of Thin Free Liquid Films from Newtonian and Viscoelastic Solution, Physical Review Letter 79, 24: 4850-4853, http://dx.doi.org/10.1103/PhysRevLett.79.4850. 